\title{
Life of learning with the fortunate few
}

\section{A.P. French}

Bird of Passage: Recollections of a Physicist. By Rudolf Peierls.

Princeton University Press:1986. Pp.350. \$29.50, £21.20.

ANY physicist who did not participate in the flowering of quantum physics during the 1920 s and 1930 s (and today of course that means all but a handful) must feel some sense of envy, mixed with a touch of awe, towards those who did. It was, truly, a heroic time, during which the secrets of the atom and then the nucleus surrendered to a band of brilliant theorists and experimenters. And, largely because the community of physicists was then relatively small, it took place in an atmosphere of scientific internationalism that has probably never been surpassed. Rudolf Peierls was one of those fortunate few, and in his autobiography he writes of his experience of it, during which his own distinguished career was launched.

Peierls, born in Berlin in 1907, entered the university there in 1925 and attended the theoretical lectures given by Max Planck, who started it all in 1900 with his discovery of the quantization of energy. It should have been an exciting beginning, but, to quote the author, "Planck's lectures were, I think, the worst I have ever attended". That first year did, however, have its compensations. Peierls learned about Bohr orbits and the quantum of action in a lecture course on X-ray physics, given by Walther Bothe. He also attended lectures by Walther Nernst, whom Peierls describes (and I cannot resist quoting him) as "a great physicist of small stature and an even smaller sense of humility" - but nonetheless a very good lecturer.

Better things were in store. In the next year he moved to Munich, where Arnold Sommerfeld, extender of Niels Bohr's atomic model and supreme teacher of theoretical physics, was the revered "Geheimrat". Here, Peierls's eyes were opened to the newest of the new. Werner Heisenberg and Erwin Schrödinger, in their different (but, as it was later shown, equivalent) ways, had just published completely fresh approaches to the problems of atomic dynamics; and the formidable Wolfgang Pauli, a former student of Sommerfeld, had introduced his famous "exclusion principle", according to which no two electrons could occupy the same quantum state. Physics was undergoing its greatest transformation since Faraday and Maxwell had unified electricity and magnetism. In 1928, in pursuit of the new knowledge, Peierls went to study under Heisenberg in Leipzig, and then, in 1929, to join Pauli in Zurich. At the end of that year he obtained his doctorate and became Pauli's assistant. But his horizons were still expanding. In 1930 he visited Bohr in Copenhagen and then, in an exciting and benignly fateful trip, attended a conference in Odessa, where he met Eugenia Nikolaevna Kannegiser from Leningrad. Little more than six months later he returned to Leningrad to marry her.

With the rise of Hitler in the 1930s, physics and politics became painfully intertwined. First came the exodus of refugees

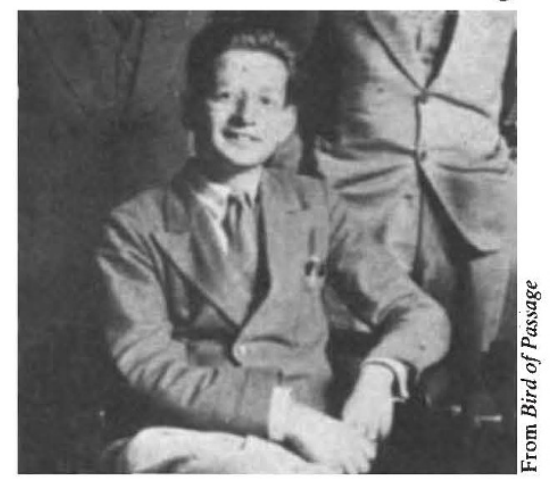

Early days - Rudolf Peierls at an informal meeting in Leipzig, 1931.

from Germany and Austria. At this time, Peierls and his wife happened to be in Britain, thanks to a Rockefeller fellowship, but it meant that there was no going back. The ultimate result was that, from 1937 to 1963 , Rudolf Peierls was professor, and leader of theoretical physics, at the University of Birmingham. During this quarter-century he built up an outstanding research school, notable alike for the catholicity of its physics and the diversity in national origins of its students.

The second major development closely related to the first - was of course the atomic bomb. It is amazing to contemplate how many of the leaders in that enterprise had been driven out by the Axis powers. Amongst the physicists, one can immediately think of Hans Bethe, Enrico Fermi, Otto Frisch, Victor Weisskopf and, of course, Peierls himself. Otto Frisch, who in Niels Bohr's Institute in 1939 had been the first to observe directly the disruption of uranium nuclei through fission (and who had given the process its name) joined Peierls at Birmingham a few months later. Early in 1940 they wrote a famous joint memorandum, spelling out in some detail the possibility of making a "super-bomb" with only a few kilograms of separated uranium-235. The idea of making an explosive based on fission had been in the air since fission was first discovered, but given the low "abundance" (only 0.7 per cent) of the easily fissionable
${ }^{235} \mathrm{U}$ in natural uranium, the belief in this possibility was about to expire when the Frisch-Peierls memorandum was sent to Sir Henry Tizard, then chairman of the Air Defence Committee. The result was the establishment, under G.P. Thomson, of the curiously named "MAUD Committee" (which, as Sir Rudolf has since remarked, was intended to be meaningless, but could have been interpreted as "Military Applications of Uranium Disintegration" - altogether too revealing!).

Two central chapters on the wartime years - divided, for Peierls, between Britain and the United States - give an excellent picture of the scientific and human context in which the atomic bomb was made. Whatever its darker implications, this was for the participants an exciting time; particularly so, perhaps, for the small group of British scientists who, like Peierls himself, joined the American project at Los Alamos, where the bomb was completed and assembled. Looking back, the youthfulness of the leading figures in this enterprise is little short of astounding. Oppenheimer was appointed Director of Los 4lamos in 1942, at the age of 38 , and Hans Bethe became head of the Theoretical Division in 1943, at age 37. Peierls himself was also 37 when he went there, succeeding Chadwick as head of the British mission. Also at Los Alamos, of course, was Klaus Fuchs, who had been brought into the project by Peierls himself in 1941 and, as Peierls describes, must have begun his leaking of atomic secrets to the Soviet Union almost immediately.

After the war it was Birmingham again, for nearly 20 years. It was a time of steady development, as new ideas in many different areas of physics made their appearance. Peierls, the generalist, welcomed them all, in what seems to have been a happy association of staff and students. It is noteworthy that a whole chapter in his book is entitled "Teaching"; he took his responsibilities seriously. After Birmingham it was Oxford - a decade of developing a strong department of theoretical physics. Then, in 1974, came a wellearned retirement.

I should have preferred to have seen somewhat more of Sir Rudolf's views on the state of physics, and less of personal anecdote. But clearly he has written the book he wanted to write, and in the process has made a enjoyable addition to the living history of twentieth-century physics. Moreover, he projects an attractive image of a talented but genuinely modest person who has made a notable contribution to the advance of education and research in physics, especially in Britain.

A.P. French is a Professor in the Department of Physics, Massachusetts Institute of Technology, Cambridge, Massachusetts 02139, USA. He was a junior member of the British "tube alloys" project, and of the British group at Los Alamos during the war. 